\title{
Nucleolar Organizer Regions (NORs) in the Chromosomes of an Aphid Lipaphis erysimi Kalt. (Homoptera: Aphididae) with Variable Chromosome Numbers
}

\author{
I. Kar and A. R. Khuda-Bukhsh \\ Department of Zoology, University of Kalyani, Kalyani-741 235, West Bengal, India
}

Accepted August 24, 1990

There is a controversy about the exact diploid number of chromosomes in Lipaphis erysimi, a polyphagous species of aphid infesting on cruciferous plants and reproducing parthenogenetically throughout the year in the plains of India. Gut (1976) reported from the Netherlands $2 \mathrm{n}=10$ chromosomes including 2 discrete dot-shaped chromosomes in L. erysimi, which was confirmed by Kurl and Mishra (1981) from Jodhpur in India. But Khuda-Bukhsh and Dutta (1981) and Khuda-Bukhsh and Pal (1984) observed $2 n=8$ chromosomes in the overwhelming majority of the metaphase spreads examined and occasionally found $2 n=10$ chromosomes including 2 discrete dots in some plates. They (Khuda-Bukhsh and Pal 1984) also encountered some plates with $2 n=9$ chromosomes including 1 dot-like chromosome. Apparently, the frequency of $2 n=8$ chromosomes was strikingly greater than $2 n=9$ or 10 chromosomes in different populations collected from 3 different hostplants and the frequencies of $2 n=9$ or 10 chromosomes seemed to vary to some extent depending on different hostplants

(Khuda-Bukhsh and Pal 1984). Thus the possibility that pinching off of a part of a chromosome or a pair of chromosomes might in fact have led to the origin of $2 n=9$ or 10 chromosomes, respectively, prompted us to undertake the present work with a view to deliniate secondary constriction zones (SCs) in the chromosomes of L. erysimi, that might in turn be of some help in ascertaining the exact diploid number and the cause of origin of the variation in diploid chromosome complements.

\section{Materials and methods}

The chromosome preparations were made from tiny embryos of apterous viviparous females of Lipahis erysimi Kalt. collected from the hostplant Brassica nigra (Fam. Cruciferae) from Kalyani, West Bengal, by deploying the routine technique described earlier (KhudaBukhsh and Pal 1985). Air-dried slides were subjected to both Giemsa and Silver-nitrate staining. Several techniques deployed to reveal the secondary constrictions (SCs) in the chromosomes of mammals and insects were attempted and the one followed by Howell and Black (1980) gave superior results.

\section{Results and discussion}

The Giemsa-stained metaphase complements (Figs. 1 and 2) and the karyotypes (Figs. 3 and 4 ) revealed $2 n=8$ chromosomes. The 8 chromosomes could be divided into two distinct size-classes: 2 large and 2 small pairs of chromosomes. The chromosomes did not show any longitudinal differentiation in the form of clear primary and/or secondary constrictions in the Giemsa-stained preparations. However, there was a round discrete silver-stained body

${ }^{1}$ Author for correspondence; dedicated to Prof. G. K. Manna on his 65 th birth anniversary. 
appearing at one terminal end of two larger chromosomes (Figs. 5-10). In most of the metaphase plates these round nucleolar organizer regions (NORs) could be easily followed. However, in some plate (Fig. 7) the SC appeared as divided into two small dots. Interestingly enough, in some spreads (Fig. 11) some degree of chromatid separation also indicated the presence of divided NORs in the two larger chromosomes. In the interphase, one or two silver-positive masses, presumably nucleolus (Figs. 12-14) could aslo be observed.

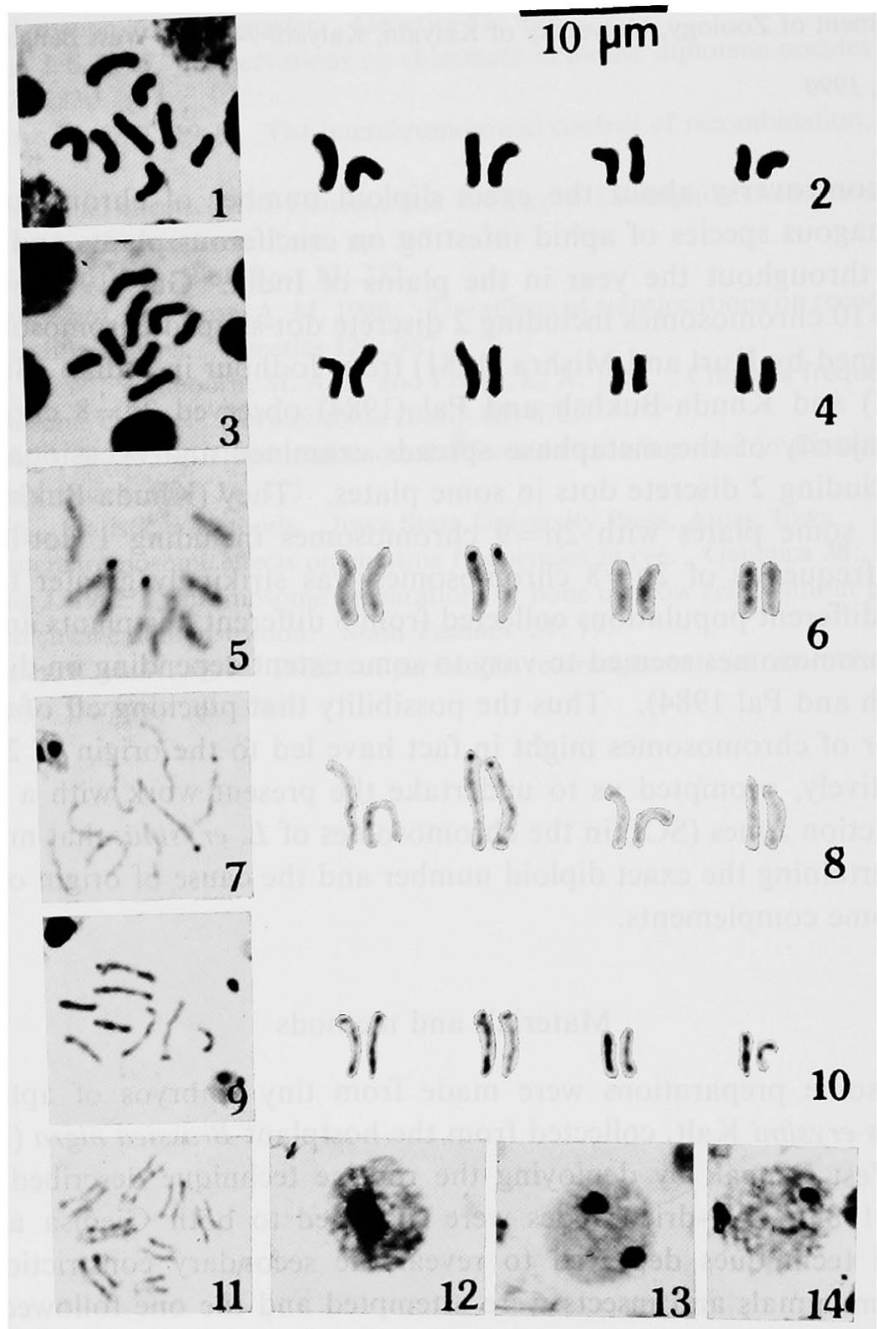

Figs. 1-14. Photomicrographs of embryonic cells of Lipaphis erysimi: Ordinary Giemsa-stained metaphase complements (Figs. 1-2) and their respective karyotypes (Figs. 3-4); Silver-stained metaphase spreads (Figs. 5-7) and their respective karyotypes (Figs. 8-10); A silver-stained metaphase spread showing separated chromatids (Fig. 11); Interphase nuclei showing one (Fig. 12) and two silver-positive masses (Figs. 13-14).

The SCs of metaphase chromosomes, known as NORs because of their association with nucleoli, are believed to be the chromosomal sites of genes coding for 18S and 28S rRNA in human and several mammalian species (Henderson et al. 1972, Henderson 1974, Henderson et al. 1974, Pardue and Hsu 1975). Although NORs have been studied in a wide group of organisms including mammals (Howell and Black 1980, Denton et al. 1976, Goodpasture and 
Bloom 1975), fish (Kligerman and Bloom 1977, Ojima and Yamano 1980, Takai and Ojima 1982, 1986, Gold 1984, Galetti et al. 1984, Mayr et al. 1986), some insects (Ruthman and Permantier 1973, Funaki et al. 1975) and some plants (Funaki et al. 1975), very limited works have so far been carried out on organisms with diffused centromeric activity (holokinetic chromosomes) (Nokkala and Nokkala 1984). From the present study, the diploid number of chromosomes in $L$. erysimi can be confirmed as $2 n=8$ as reported earlier by Khuda-Bukhsh and Dutta (1981) and Khuda-Bukhsh and Pal (1984). It is quite possible that detachment of the fragment at the SC sites in one or two chromosomes would account for the occasional findings of $2 n=9$ or 10 chromosomes as fragmentation/fusion mechanism has been repeatedly claimed by many workers in the karyotypic evolution of aphids in general (Blackman $1980 \mathrm{a}, \mathrm{b}$, Kuznetsova 1980, White 1973, Khuda-Bukhsh and Kar 1989). Although the N-banding pattern in L. erysimi chromosomes was very similar to that of Macrosiphoniella sanborni, the only other species of aphid worked out so far (Kar and Khuda-Bukhsh 1990), the pattern differed strikingly from what has been observed in Coreus marginatus (Nokkala and Nokkala 1984), a hemipteran insect with holokinetic chromosomes. In $C$. marginatus, N-banding was demonstrated to represent lateral differentiation along the axial core and showed similar behaviour as kinetochore structure in the holokinetic chromosomes (White 1973), which could not be observed in the aphid materials also believed to have holokinetic chromosomes. Further information on N-band localization in chromosomes of other members of this group of tiny pest insects would be of interest to understand the structural organization in them more precisely.

\section{Summary}

The diploid number of 10 chromosomes has been claimed by some workers in Lipaphis erysimi, a polyphagous species of aphid while the diploid number of 8 was suggested by others. In the present study, both Giemsa-stained and Silver-nitrate stained preparations confirmed $2 n=8$ chromosomes in $L$. erysimi, and the NORs were revealed as a discrete silver-positive dot at one end of two large-sized chromosomes. It has been hypothesized that the dissociation of one or two fragments at SC sites might have led to the origin of $2 n=9$ or 10 chromosomes which have occasionally been observed by various workers.

\section{Acknowledgements}

Grateful acknowledgement is made to CSIR, Government of India, New Delhi, for the financial support of the work.

\section{References}

Blackman, R. L. 1980a. Insect Cytogenetics. Sym. Roy. Entomol. Soc., London, No. 10. (Eds. R. L. Blackman, G. M. Hewitt and D. Ashburner), pp. 133-148.

- 1980b. Chromosome numbers in the Aphididae and their taxonomic significance. Syst. Ent. 5: 7-25.

Denton, T. E., Howell, W. M. and Barrett, J. U. 1976. Human nucleolar organizer chromosomes: Satellite association. Chromosoma 55: 81-84.

Funaki, K., Matsui, S. and Sasaki, M. 1975. Location of nucleolar organizers in animal and plant chromosomes by means of an improved N-banding technique. Chromosoma 49: 357-370.

Galetti Jr., P. M., Foresti, F., Bertollo, A. C. and Moreira, F. O. 1984. Characterization of eight species of Anostomidae (Cyprinifiormes) fish on the basis of nucleolar organizer region. Caryologia 37: 401406.

Gold, J. R. 1984. Silver staining and heteromorphism of chromosomal nucleolar organizer region in North Amerian cyprinid fishes. Copeia 1984: 133-139.

Goodpasture, C. and Bloom, S. E. 1975. Visulalization of nucleolar organizer region in mammalian chro- 
mosomes using silver staining. Chromosoma 53: 37-50

Gut, J. 1976. Chromosome numbers of parthenogenetic females of fiftyfive species of Aphididae (Homoptera) new to cytology. Genetica 46(3): 279-285.

Henderson, A. S., Warburton, D. and Atwood, K. C. 1972. Location of rDNA in the human chromosome complements. Proc. Natl. Acad. Sci., U. S. A. 69: 3394-3398.

- 1974. Location of rDNA in the chromosome complement of the rhesus (Macaca mulatta). Chromosoma 44: 367-370.

-, Eicher, E. M., Yu, M. T. and Atwood, K. C. 1974. The chromosomal location of ribosomal DNA in the mouse. Chromosoma 49: 155-160.

Howell, W. M. and Black, D. A. 1980. Controlled Silver-staining of nucleolus organizer regions with a protective colloidal developer: A 1-step method. Experientia 36: 1014-1015.

Kar, I. and Khuda-Bukhsh, A. R. 1990. N-banding on the metaphase chromosomes of an aphid Macrosiphoniella sanborni (Homoptera: Aphididae). Genetica (Communicated)

Khuda-Bukhsh, A. R. and Dutta, S. 1981. Somatic chromosomes of four species of aphids (Aphididae: Homoptera). In: Pers. in Cytol. and Genet., Proc. 3rd All Ind. Cong. Cytol. \& Genet., (Eds. G. K. Manna and U. Sinha), Hindasia Publ., New Delhi, 3: 121-124.

- and Kar, 1. 1989. C-banding on the chromosomes of a common polyphagous aphid, Aphis gossypii (Homoptera: aphididae): Indication of structural rearrangements. Entomon 14 (1 \&2): 11-14.

- and Pal, N. B. 1984. A further cytological investigation on Lipaphis erysimi (Homptera: Aphididae): Chromosomal variations. In: Pers. in Cytol. and Genet., Proc. 4th All Ind. Cong. Cytol. \& Genet., (Eds. G. K. Manna and U. Sinha), Hindasia Publ., New Delhi, 4: 403-409.

- and - 1985. Cytogenetical studies on aphids (Homoptera: Aphididae) from India: I. Karyomorphology of eight species of Aphis. Entomon 10(2): 171-177.

Kligerman, A. D. and Bloom, S. E. 1977. Distribution of F-body heterochromatin and nucleolar organizers in the genome of the central mudminnow, Umbra limi. Cytogenet. Cell Genet. 18: 182-196.

Kurl, S. P. and Misra, S. D. 1981. Studies on the mitotic chromosomes of two species of aphids (Homoptera: Aphididae). In. Pers. in Cytol. and Genet., Proc. 3rd All Ind. Cong. Cytol. \& Genet., (Eds. G. K. Manna and U. Sinha), Hindasia Publ., New Delhi. 3: 125-129.

Kuznetsova. V. G. 1980. The way of karyotype evolution in insects with holokinetic chromosomes. Insect integrat-taxonomy, 16 Internatatl. Congr. Entomol. pp. 85-89 a-b.

Mayr, B., Rab, P. and Kalat, M. 1986. Localization of NORs and counterstain-enhanced fluorescence in Salmo gairdneri and Salmo trutta (Pisces, Salmonidae). Theor. Appl. Genet. 71: 703-707.

Nokkala, S. and Nokkala, C. 1984. N-banding pattern of holokinetic chromosomes and its relation to chromosome structure. Hereditas 100: 61-65.

Ojima, Y. and Yamano, T. 1980. The assignment of the nucleolar organizer in the chromosomes of the funa (Carassius, Cyprinidae, Pisces). Proc. Japan Acad., 51B: 701-706.

Pardue, M. L. and Hsu, T. C. 1975 . Location of $18 \mathrm{~S}$ and $28 \mathrm{~S}$ ribosomal genes on the chromosomes of the Indian Muntjac. J. Cell Biol. 64: 251-254.

Ruthman, A. and Permantier, Y. 1973. Spindel und Kinetochoren in der Mitose und Meiose der Baumwollwanze Dysdercus inermedius (Heteroptera). Chromosoma 41: 271-288.

Takai, A. and Ojima, Y. 1982. The assignment of the nucleolus organizer regions in the chromosomes of the carp, the funa, and their hybrids (Cyprinidae, Pisces). Proc. Japan Acad., 58B: 303-306.

- and - 1986. Some features of Nucleolus Organizer Regions in fish chromosomes. In. Indo-Pacific Fish Biology. Proc. 2nd Internatl. Conf. on Indo-Pacific fishes. (Eds. T. Uyeno, R. Arai, T. Taniuchi and K. Matsuura), Ichthyol. Soc. of Jap., pp. 899-909.

White, M. J. D. 1973. Animal Cytology and Evolution. University Press, Cambridge, (3rd Edn.), p. 961. 